\title{
Efficacy of bisulfite modification and DNA recovery using commercial kits from samples of genomic and circulating DNA
}

\author{
Olga Bryzgunova ${ }^{1,}$ *, Pavel Laktionov ${ }^{1}$, Tatyana Skvortsova ${ }^{1}$, Anna Bondar ${ }^{1}$, Evgeniy Morozkin $^{1}$, \\ Alena Lebedeva ${ }^{1}$, Valentin Vlassov ${ }^{1}$, Kurt Miller ${ }^{2}$, Hans Krause $^{2}$ \\ ${ }^{1}$ Institute of Chemical Biology and Fundamental Medicine, Siberian Branch of the Russian Academy of Sciences, pr. Lavrentieva 8, \\ Novosibirsk, Russia \\ ${ }^{2}$ Charite-Universitatsmedizin Berlin, Campus Mitte (CCM), Department of Urology, Chariteplatz, Berlin, Germany
}

\section{Email address:}

olga.bryzgunova@niboch.nsc.ru(O.Bryzgunova)

\section{To cite this article:}

Olga Bryzgunova, Pavel Laktionov, Tatyana Skvortsova, Anna Bondar, Evgeniy Morozkin, Alena Lebedeva, Valentin Vlassov, Kurt Miller, Hans Krause. Efficacy of Bisulfite Modification and DNA Recovery Using Commercial Kits from Samples of Genomic and Circulating DNA, Computational Biology and Bioinformatics. Vol. 1, No. 6, 2013, pp. 28-36. doi: 10.11648/j.cbb.20130106.11

\begin{abstract}
This study had evaluated three commercially available bisulfite modification kits with regard to the procedural DNA loss and the efficacy of cytosine conversion to uracil. The efficacy of DNA conversion was estimated by pyrosequencing of eight $\mathrm{CpG}$ sites of unmethylated and fully enzymatically methylated templates of RAR $\beta$ gene promoter region and cirDNAs of healthy donors and prostate cancer patients. The procedural DNA loss was calculated by methylindependent qPCR for ubiquitously distributed L1RE1 retrotransposable elements. Our data demonstrates that all commercial kits displayed similar conversion efficacy of the unmethylated cytosines close to $99 \%$ independently of DNA concentration. However, when low DNA concentrations were used, the observed basic level of genomic DNA methylation increased to $11 \%$ depending on the position of CpG site. Qiagen and Chemicon kits recovered no more than $20 \%$ starting material at a high DNA input (500 ng/probe) and only $2.7-5.8 \%$ for low DNA input (10 ng/probe). EZ DNA MethylationGold Kit from Zymo Research provided the highest recovery regardless of the initial DNA input with average rates of no less than $86 \%$. These results suggest that the EZ DNA Methylation-Gold Kit is the most appropriate tool for bisulfite modification of cirDNA when assaying DNA in low amounts.
\end{abstract}

Keywords: DNA Methylation, Bisulfite Conversion, Pyrosequensing

\section{Introduction}

To detect methylated sequences even in the presence of excess amounts of unmethylated templates, the majority of technologies rely on sodium bisulfite modification of the input material, which converts the epigenetic DNA differences into genetic ones. In particular, unmethylated cytosine nucleotides are converted to thymidines (by uracil), whereas methylated cytosines $(5 \mathrm{mC})$ still pair as cytosines. Since subsequent analyses, like methylationspecific PCR (MSP) or sequencing, rely on the differentiation between methylated and unmethylated cytosine residues, the incorrect performance of the procedure greatly influence the further results. When analyzing minute amounts of DNA like cirDNA in a cancer diagnostic setting, it is of paramount importance to avoid any DNA loss during the several manipulation steps, especially involving bisulfite modification itself or the accompanying DNA recovery [1]. Efficacy of DNA conversion and recovery also interferes with data of pyrosequencing or Massive Parallel Sequencing data.

The efficacy of bisulfite modification protocols is extremely important in relation to the endogenous cell-free DNAs circulating in the blood (cirDNA), which represents a valuable source of material for non-invasive cancer diagnosis [2, 3]. Indeed, concentrations of cirDNA in the plasma of healthy/cancer persons vary between $10 \mathrm{ng} / \mathrm{ml}$ and hundreds of nanograms per milliliter [3, 4]; cirDNA are strongly fragmented and cirDNA from tumor cells circulate in excess of cirDNA from the normal cells [3]. Aberrantly methylated DNAs are among the most sensitive 
and specific cirDNA cancer markers not only because they are frequently found in cancer but also because bisulfate modification provides detection of aberrantly methylated targets in the large excess of unmethylated one [5]. Thus, bisulfite DNA conversion eventually determines the sensitivity and specificity of subsequent cirDNA analysis.

This study has evaluated the efficacy of three commercially available bisulfite modification kits for treatment of cirDNA with regard to procedural DNA loss and the efficacy of cytosine conversion to uracil.

\section{Materials and Methods}

\subsection{Sample Collection and Treatment}

Blood samples of 70 healthy donors (19-63 years old) and 20 previously untreated prostate cancer patients (pT2$3 \mathrm{pN} 0$-xpM0-x, 45-78 years old) were obtained from the Central Clinical Hospital and Municipal Clinical Hospital no. 1, Novosibirsk, Russia. The experimental protocol was approved by the Ethics Committees of the Hospitals, and informed consent was obtained from all patients involved in the study. Venous blood was collected and plasma was separated as earlier described [6].

To obtain the preparations for analysis, individual samples of the healthy blood plasma were pooled (1-ml sample from each donor) to obtain the specimen of $70 \mathrm{ml}$; analogously, 20 individual 1-ml samples of prostate cancer patients were pooled to give the specimen of $20 \mathrm{ml}$. CirDNAs were isolated using the Blood Plasma DNA Isolation Kit (BioSilica Ltd., Novosibirsk, Russia) [7] according to the manufacturer's instructions and eluted into nuclease-free water. Genomic DNA (by definition [8], unmethylated in the region of RARbeta2 gene promoter) was isolated from leukocytes of healthy donors using Genomic DNA Isolation Kit (BioSilica Ltd., Novosibirsk, Russia). Fully methylated genomic DNA was obtained from Millipore (Billerica, MA, United States). DNA concentrations and purity were determined by $\mathrm{OD}_{260} / \mathrm{OD}_{280}$
(Genesys 10 UV, Thermo Electronics, United States).

\subsection{DNA Modification}

The genomic (10 or $500 \mathrm{ng}$ ) and cirDNAs from patients $(80 \mathrm{ng})$ were modified by treatment with sodium bisulfite using the following kits; EpiTect Bisulfite Kit (Qiagen, Hilden, Germany; Catalog no. 59104), EZ DNA Methylation-Gold Kit (Zymo Research, Irvine, CA, United states; Catalog no. D5006), and CpGenome Fast DNA Modification Kit (Chemicon, Temecula, CA, United States; Catalog no. S7824) as recommended by manufactures. Eluted DNAs were brought to equal volumes $(40 \mu 1)$. All experiments were repeated twice and in duplicates for each experimental point.

\subsection{Quantification of DNA before and after Modification}

Genomic and cirDNA were quantified using methylindependent quantitative real-time PCR (Q-PCR) for detection of the reverse chain of LINE1 elements. Q-PCR was performed in an ICycler iQ5 (Bio-Rad, Hercules, CA, United States). Oligonucleotides were synthesized at the Laboratory of Medical Chemistry, Institute of Chemical Biology and Fundamental Medicine, Siberian Branch of the Russian Academy of Sciences, Novosibirsk, Russia. Sequences of all primers and PCR conditions are listed in Table 1. The PCR mixture $(30 \mu \mathrm{l})$ contained $5 \mu \mathrm{l}$ of DNA template, $1.5 \mu \mathrm{l}$ of 1000 -fold diluted SYBR Green I, $10 \mathrm{nM}$ fluorescein, $300 \mathrm{nM}$ of each primer, $0.25 \mathrm{mM}$ of each dNTP, $1 \mathrm{U}$ of $\mathrm{Taq}$ polymerase (Fermentas, Vilnius, Lithuania), and Taq polymerase buffer ( $65 \mathrm{mM}$ Tris- $\mathrm{HCl}$ $\mathrm{pH} 8.8,16 \mathrm{mM}\left(\mathrm{NH}_{4}\right)_{2} \mathrm{SO}_{4}, 0.05 \%$ Tween 20 , and $3.5 \mathrm{mM}$ $\mathrm{MgCl}_{2}$ ). The PCR products amplified from bisulfite, treated/untreated DNA were used as standards for DNA quantification before and after conversion respectively. The accuracy (variation coefficient) of real-time PCR was 7\% and sensitivity, 230 copies of PCR product per reaction (equal to $0.5 \mathrm{pg}$ of genomic DNA), the efficacy $98,3-99,2 \%$.

Table 1. Primers and PCR conditions.

\begin{tabular}{|c|c|c|c|}
\hline Target sequence & Primer sequences $\left(5^{\prime}-3^{\prime}\right)$ & PCR conditions & Product size, bp \\
\hline $\begin{array}{l}\text { L1RE1, LINE1 retrotransposable } \\
\text { element 1(AL162574.14, 162925-163131) }\end{array}$ & $\mathrm{R}$ : acttacactcccacacaata & $\begin{array}{l}180 \mathrm{~s}-95^{\circ} \mathrm{C}, \\
\left(25 \mathrm{~s}-95^{\circ} \mathrm{C},\right. \\
15 \mathrm{~s}-60^{\circ} \mathrm{C}, \\
\left.40 \mathrm{~s}-72^{\circ} \mathrm{C}\right) \times 40\end{array}$ & 207 \\
\hline $\begin{array}{l}\text { RARbeta2, retinoic acid receptor, beta, } \\
\text { isoform } 2 \text { [Homo sapiens], wild-type } \\
(\mathrm{X} 56849.1,924-1117)\end{array}$ & F: atgcgagctgtttgaggact & $\begin{array}{l}3 \mathrm{~min}-95^{\circ} \mathrm{C}, \\
\left(25 \mathrm{~s}-95^{\circ} \mathrm{C},\right. \\
15 \mathrm{~s}-64.5^{\circ} \mathrm{C}, \\
\left.40 \mathrm{~s}-72^{\circ} \mathrm{C}\right) \times 40, \\
5 \min -72^{\circ} \mathrm{C}\end{array}$ & 192 \\
\hline $\begin{array}{l}\text { RARbeta2, retinoic acid receptor, beta, } \\
\text { isoform } 2 \text { [Homo sapiens], external } \\
\text { (X56849.1, } 858-1128 \text { ) }\end{array}$ & $\begin{array}{l}\text { F: ggaagtgagttgtttagaggtt } \\
\text { R: caaataatcatttaccattttcca }\end{array}$ & $\begin{array}{l}3 \mathrm{~min}-95^{\circ} \mathrm{C}, \\
\left(20 \mathrm{~s}-95^{\circ} \mathrm{C},\right. \\
10 \mathrm{~s}-54^{\circ} \mathrm{C}, \\
\left.30 \mathrm{~s}-72^{\circ} \mathrm{C}\right) \times 40,\end{array}$ & 269 \\
\hline
\end{tabular}




\begin{tabular}{|c|c|c|c|}
\hline Target sequence & Primer sequences $\left(5^{\prime}-3^{\prime}\right)$ & PCR conditions & Product size, bp \\
\hline \multirow{6}{*}{$\begin{array}{l}\text { RARbeta2, retinoic acid receptor, beta, } \\
\text { isoform } 2 \text { [Homo sapiens], internal } \\
\text { (X56849.1, 930-1116) }\end{array}$} & & $5 \min -72^{\circ} \mathrm{C}$ & \\
\hline & F: ttgtttgaggattgggatgt & $3 \min -95^{\circ} \mathrm{C}$ & \\
\hline & & $\left(20 \mathrm{~s}-95^{\circ} \mathrm{C}\right.$ & \\
\hline & R: biotin-taccattttccaaacttactc & $10 \mathrm{~s}-54^{\circ} \mathrm{C}$ & 186 \\
\hline & & $\left.30 \mathrm{~s}-72^{\circ} \mathrm{C}\right) \times 20$, & \\
\hline & & $5 \min -72^{\circ} \mathrm{C}$ & \\
\hline $\begin{array}{l}\text { RARbeta2, sequencing primer } \\
\text { (X56849.1, 930-950) }\end{array}$ & ttgtttgaggattgggatgt & $*$ & 68 \\
\hline
\end{tabular}

*Pyrosequencing was performed as described in the text.

\subsection{Estimation of Pyrosequencing Accuracy and Sensitivity}

Solutions with a known ratio of unmethylated to completely methylated PCR products were used for estimation of the accuracy and sensitivity of pyrosequencing platform. To obtain unmethylated PCR products, $50 \mathrm{ng}$ genomic DNA from HUVEC cells was amplified using RARbeta2 wild-type primers (Table 1, N3 and N4) in a conventional PCR. The PCR mixture $(30 \mu \mathrm{l})$ contained $5 \mu \mathrm{l}$ of DNA template, Taq polymerase buffer (65 mM Tris- $\mathrm{HCl} \mathrm{pH}$ 8.8, $16 \mathrm{mM}\left(\mathrm{NH}_{4}\right)_{2} \mathrm{SO}_{4}, 0.05 \%$ Tween-20, and $\left.2 \mathrm{mM} \mathrm{MgCl}_{2}\right), 0.25 \mathrm{mM}$ of each dNTP, $1 \mathrm{U}$ of Taq polymerase (Fermentas, Vilnius, Lithuania), and 300 $\mathrm{nM}$ of each primer. The PCR conditions are given in Table 1. The PCR products were purified by non-denaturing $6 \%$ PAGE and subsequent electroelution. Part of PCR product was treated with SssI methylase (New England BioLabs, Ipswich, MA, United States) as recommended by the manufacturers and purified using a PCR Product Isolation Kit (BioSilica Ltd., Novosibirsk, Russia). Both PCR products were quantified by $\mathrm{OD}_{260}$ (Genesys $10 \mathrm{UV}$, Thermo Electronics, United States).

Completely methylated and completely unmethylated PCR products were combined to obtain a panel of methylation standards contained $0,2.5,5,10,50$, and $100 \%$ of methylated DNA with a final DNA concentration of 1 $\mathrm{pg} / \mu 1$. The degree of methylation of the standards was determined by pyrosequencing as described below. Methylated standards were modified with an EZ DNA Methylation-Gold Kit according to the manufacturer's protocol (Zymo Research). DNA (5 $\mu \mathrm{l})$ was amplified with biotinylated RARbeta2 internal primers in a conventional PCR as described above (PCR conditions are given in Table 1) for subsequent pyrosequencing immediately after bisulfite modification. Single-stranded biotinylated DNA were isolated using streptavidin coated beads on a Pyrosequencing workstation (Pyrosequencing AB, Uppsala, Sweden). Pyrosequencing was performed in a PSQ 96MA (Pyrosequencing AB, Sweden) device using a PyroGold SQA reagent kit (Pyrosequencing $\mathrm{AB}$, Sweden) and 0.45 $\mu \mathrm{M}$ sequencing primer (Table 1) according to the manufacturer's protocol.

\subsection{Pyrosequencing of Genomic and Circulating DNAs}

CirDNA was extracted from the samples and bisulfitemodified as described above. DNA was amplified in two steps by nested PCR: $5 \mu$ of DNA per reaction were amplified at the first PCR step with external primers and $1 \mu \mathrm{l}$ of the obtained PCR products was reamplified at the second step with internal primers. The composition of PCR mixture was similar to that described above for conventional PCR. Pyrosequencing was done as earlier described. The primers and PCR conditions are listed in Table 1.The genomic DNA from leukocytes of healthy donors or universal methylated genomic DNA obtained from Millipore (10 and $500 \mathrm{ng}$ ) was amplified in two-step PCR and pyrosequenced as described for cirDNA. Pyrosequencing was done in duplicates for each experimental point.

\section{Results}

The bisulfite-based methods have been successfully used for methylation analysis of DNA from various sources [914]. These methods are based on the selective deamination of cytosine to uracil by treatment with sodium bisulfite and subsequent PCR-based assays (MS-PCR, Q-MS-PCR, bisulfite sequencing, COBRA, microarrays and pyrosequencing). During PCR amplification of bisulfitemodified DNA, original cytosines appear as thymine, while 5-methylcytosines $(5 \mathrm{mC})$ appear as cytosine. The ideal bisulfite DNA conversion protocol must provide a complete conversion of cytosine residues to uracil, whereas all $5 \mathrm{mC}$ should remain intact. In addition, the loss of DNA during the modification reaction due to non-specific degradation and at the re-isolation steps should be kept as small as possible.

The aberrantly methylated DNAs released into the circulating blood by tumor cells are expected to be convenient markers for non-invasive tumor diagnostics [5]. However, fragmentation of cirDNA along with minute amounts of tumor-specific aberrantly methylated DNA circulating in the excess of unmethylated "normal" cellfree DNA demands very efficient protocols of bisulfite conversion minimizing the false DNA conversion and any DNA loss. 
To evaluate the DNA loss after chemical conversion, DNA was quantified using methylation independent QPCR for detection of LINE1 elements. To obtain a sufficient number of identical samples of cirDNA from healthy donors and cancer patients, separate samples from different donors were combined to obtain "healthy" and "cancer" blood plasma. Pooling of separate samples was required for accurate comparison of the data of subsequent tests. To estimate the efficacy of bisulfite treatment, we first characterized the accuracy and reproducibility provided by the pyrosequencing platform in question, and then assessed the methylation level of each cytosine in the examined RARbeta2 region (Fig. 1) after DNA conversion with using 3 kits.

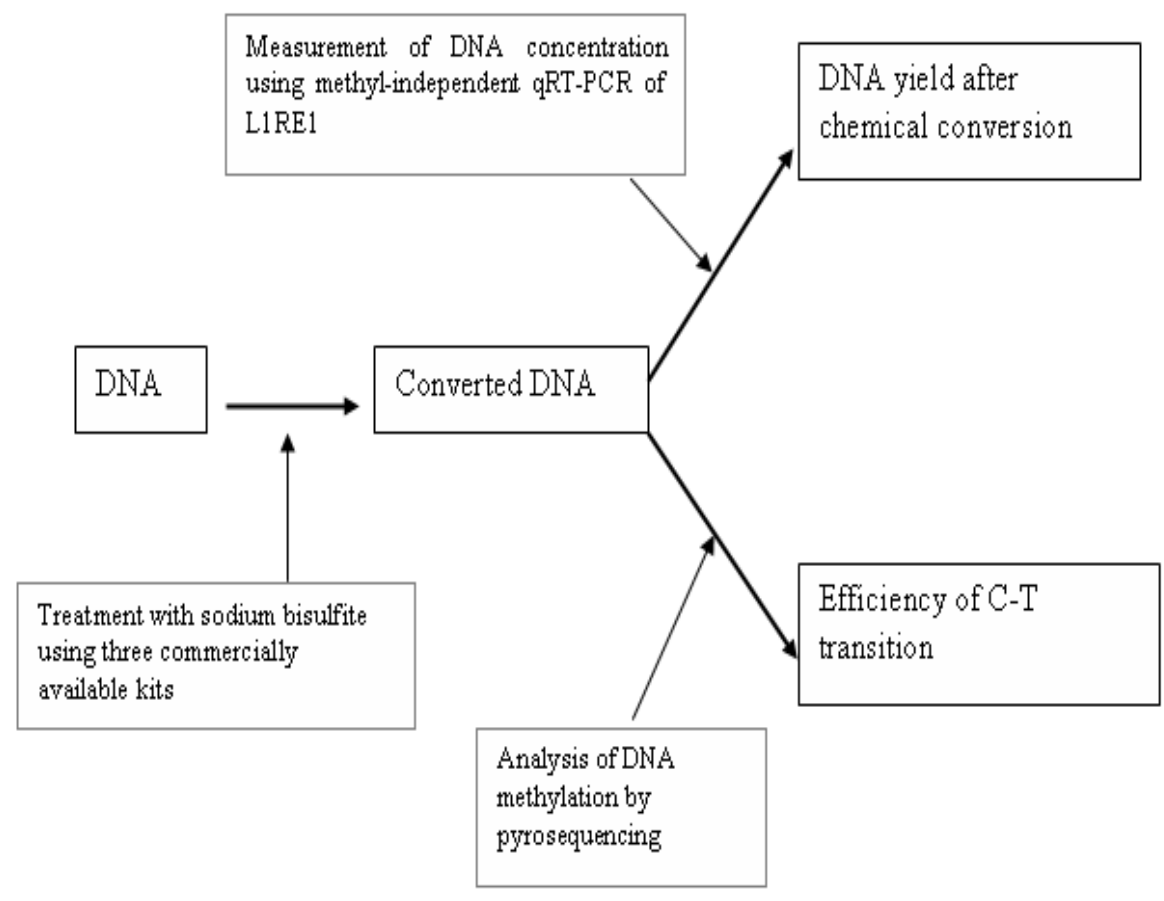

Figure. 1. Scheme of experiments. To evaluate DNA loss after chemical conversion, DNA was quantified using methylation-independent qPCR for detection of L1RE1 elements. To estimate the efficacy of bisulfite treatment, first, the accuracy and reproducibility of the pyrosequencing platform was characterized and then the methylation level of each cytosine in the studied RARbeta 2 region.

\subsection{Accuracy of Evaluation of the Degree of Methylation Using Pyrosequencing Platform}

Pyrosequencing was recently adapted to study DNA methylation and, thus, become a useful tool for determination of the global DNA methylation content of a sample [15-17]. For this purpose, pyrosequencing is ideal epigenotype-mapping tool, realized as Pyrosequencing workstation (Pyrosequencing AB, Uppsala, Sweden), which is able to quantitatively analyze up to $10 \mathrm{CpG}$ sites in a single sequencing run of 80 nucleotides [18].

The method of bisulfite modification is based on modification of cytosine (in contrast to 5 methyl cytosine) with bisulfate with subsequent deamination of cytosine but not $5 \mathrm{mC}$. It was shown that reaction efficacy depends on time, temperature and bisulfite concentration [4], and hypo- and over-modification can occur, demanding accurate selection of the conditions of modification/deamination. As is shown earlier [19], pyrosequencing-based DNA analysis determines methylation with an accuracy of $3-5 \%$. To validate the accuracy and sensitivity of our pyrosequencing assay, we used the panel of methylation standards that contained 0 ,
$2.5,5,10,50$, and $100 \%$ of methylated DNA. The average methylation of eight studied CpG sites of RARbeta2 (Fig. 2) gene was determined using one sequencing primer (Table 1). The average mean, minimum, and maximum levels of methylation (expressed as a percentage) were then determined for each DNA mixture. As is shown in Table 2, there was a slight overestimation of methylation levels in the mixtures containing a very low rate of methylated DNA $(0,2.5,5$, and $10 \%$ mixtures $)$ and a very clear underestimation of methylation level in the mixture containing $100 \%$ of methylated DNA. Nevertheless, the correlation between the methylation level detected in pyrosequencing assay and the rate of methylated DNA is linear. The mean of Pearson coefficient is 0.999 . Pyrosequencing showed a mean accuracy rate of $96 \%$ (range, 92\% for the mixture containing 100\% methylated DNA to $97.6 \%$ for the mixture containing $2.5 \%$ methylated DNA; Table 2). In addition, to evaluate the variation of pyrosequencing assay, three independent sequencing runs were performed using the panel of methylation standards. The degree of methylation at individual $\mathrm{CpG}$ sites showed a high reproducibility with a mean variation of $1.5 \%$ (range, 0.0 to 6.1 for individual $\mathrm{CpG}$ sites). 
Table 2. Degree of methylation of individual cytosines determined by pyrosequencing of the mixtures with a known content of unmethylated and methylated PCR products.

\begin{tabular}{|c|c|c|c|c|c|c|c|c|}
\hline \multirow{2}{*}{$\begin{array}{l}\text { Content of methylated } \\
\text { PCR-product, } \%\end{array}$} & \multicolumn{8}{|c|}{ Mean* degree of methylation, \%, and (SD) for individual CpG sites (1-8) } \\
\hline & 1 & 2 & 3 & 4 & 5 & 6 & 7 & 8 \\
\hline \multirow{2}{*}{100} & 95.4 & 82 & 95.4 & 95 & 98.8 & 96.4 & 95.2 & 93.8 \\
\hline & $(1.8)$ & $(0.7)$ & $(1.1)$ & $(1.4)$ & $(1.6)$ & $(0.9)$ & (1.3) & (1.6) \\
\hline \multirow{2}{*}{50} & 50.4 & 47.2 & 49.8 & 48.2 & 55.6 & 56.2 & 52.2 & 53.8 \\
\hline & (3.4) & (3.7) & $(2.5)$ & (2.9) & $(4.1)$ & $(6.1)$ & (4.7) & (5.4) \\
\hline \multirow{2}{*}{10} & 12.6 & 13 & 11.2 & 10.6 & 15 & 15.2 & 12.8 & 15.8 \\
\hline & $(0.5)$ & (1.9) & $(0.8)$ & $(0.5)$ & $(1.2)$ & (1.6) & $(0.8)$ & (2.2) \\
\hline \multirow{2}{*}{5} & 7 & 6.8 & 7 & 7 & 8.6 & 8 & 7.2 & 8.4 \\
\hline & $(0.0)$ & $(0.8)$ & $(0.0)$ & $(0.7)$ & $(0.5)$ & $(0.0)$ & $(0.4)$ & (1.5) \\
\hline \multirow{2}{*}{2.5} & 4.4 & 4.4 & 3.4 & 2.8 & 5 & 5.6 & 4 & 6.2 \\
\hline & $(0.9)$ & $(0.9)$ & $(0.5)$ & (1.6) & $(0.0)$ & (1.3) & $(0.0)$ & (1.6) \\
\hline \multirow{2}{*}{0} & 2.6 & 2.6 & 2.6 & 2.2 & 3.2 & 2.6 & 2.4 & 4.2 \\
\hline & $(0.5)$ & $(0.9)$ & $(0.5)$ & $(0.8)$ & $(0.4)$ & $(0.5)$ & (1.8) & $(0.8)$ \\
\hline
\end{tabular}

* The mean was calculated for three independent runs.

Genbank X56849 (859-1128)

ggaagtgagctgttcagaggecaggaggotctattctttgccaaaggggggaccagaattcc cccatgcgagctgtttgaggac
(1) (2) (3) (4) (5)
(6) (7)
(8)

tgggatgccgagaacgcgagcgatccgagcaggotttgttegggcaccgtcggggtaggatccggaacgcattcggaaggctt

$\longrightarrow$

atggtaaatgatcatttg

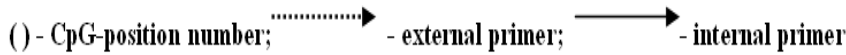

Figure. 2. Location of the primers used for PCR and pyrosequencing of the promoter region of RARbeta2 gene. Potentially methylated sites are marked grey.

\subsection{Efficacy of DNA Conversion after Modification with Different Commercial Kits}

The genomic DNA from leukocytes of healthy donors unmethylated in the analyzed region of RARbeta2 gene and universally methylated genomic DNA obtained from Millipore, along with the cirDNA isolated from the plasma of healthy donors and prostate cancer patients were treated with different kits to evaluate the degree of individual $\mathrm{CpG}$ cytosine methylation by pyrosequencing. Comparison of the average methylation of all $\mathrm{CpG}$ sites demonstrates that all kits give a similar level of DNA conversion/overconversion (Table 3). The levels of individual cytosine methylation in unmethylated and methylated DNAs along with in the cirDNA from healthy donors and prostate cancer patients determined by different kits varied insignificantly. The same DNA preparations were used in all experiments; thus, the non-coincidence of the data of individual $\mathrm{CpG}$ methylation is obviously related to the compositions of kits and the treatment protocols. 
Table 3. Degree of methylation (\%) of individual cytosines in the Cp G dinucleotides of RARbeta2 gene (X56849.1, 951-1007).

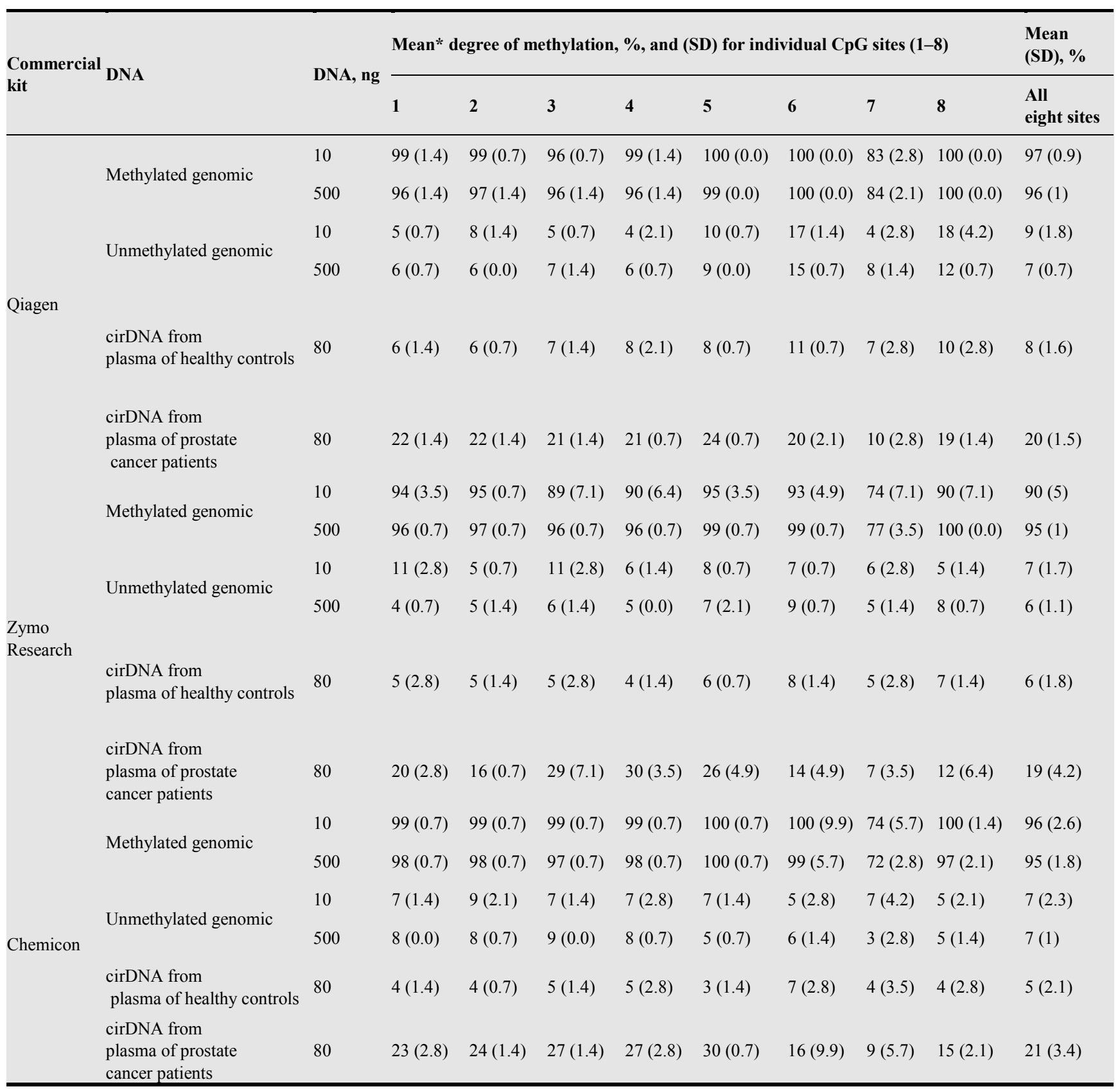

Pyrosequencing of methylated DNA demonstrates that the methylated cytosines are stable to bisulfite conversion by all commercial protocols. The degree of methylation of individual cytosines contained in the genomic DNA and cirDNA from healthy donors amounts to $4-11 \%$ for the Zymo Research kit, 6-17\% for the Qiagen kit, and 3-9\% for the Chemicon kit. Pyrosequencing of the unmethylated PCR product treated with Zymo Research kit demonstrated up to $4 \%$ methylation of individual cytosines. Thus, an incomplete cytosine conversion is only partially responsible for an increased methylation of cytosines in the DNA from healthy donors, which obviously have low but detectable level of basic methylation [13]. The reagents from Chemicon and Zymo Research provide the least level of incomplete cytosine conversion.

\subsection{DNA Recovery after Modification with Different Commercial Kits}

A minute amount of free DNA circulating in the blood [3], fragmentation of cirDNA [3], and the presentation of different DNA sequences in the pool of cirDNA nonequivalent to genomic DNA $[3,13,21]$ demand an appropriate method for measuring the cirDNA concentration [3]. As much as $80 \mathrm{ng}$ of cirDNA was used to provide a credible data in the tested range of cirDNA concentrations after bisulfate conversion, as medium DNA amount extracted from $1 \mathrm{ml}$ of prostate cancer patients plasma. 
We have earlier demonstrated that qPCR of LINE1 elements, uniformly distributed in the human genome, is an adequate method for estimating the genomic or cirDNA at minute concentrations [20]. To evaluate the DNA yield after modification with different commercial kits, the qPCR was elaborated for L1RE1, a LINE1 retrotransposable element, with a methyl-independent primer to the reverse strand that lacked cytosines in the primer recognition site [20]. Since the bisulfite conversion of the internal region that contains cytosines interferes with the melting temperature of PCR products, two PCR products were prepared for PCR calibration: one from untreated DNA and the other from bisulfite-treated DNA (untrPCR product and bstrPCR product, respectively). To measure the concentration of native DNA, untrPCR product was used for calibration, and bstrPCR product was used as a calibration standard to measure the concentration of bisulfite-treated DNA. The discrepancy between the calibration plots constructed with untrPCR and bstrPCR products were undetectable at the concentrations exceeding $50 \mathrm{pg} / \mathrm{probe}$ but reached $40 \%$ when $0.5 \mathrm{fg}$ of the PCR products were compared by qPCR. Since all the tested kits demonstrate similar level of cytosine conversion (Table 3 ), such a strategy for PCR calibration for measuring of DNA concentration appears to be reasonable.

The efficacy and reproducibility of DNA recovery were evaluated from the data on the yield of DNA \pm SD (Table 4). Processing of $500 \mathrm{ng}$ of unmethylated or methylated genomic DNA with EpiTect Bisulfite Kit (Qiagen) and CpGenome Fast DNA Modification Kit (Chemicon) yielded a similar quantity of DNA, namely, about $20 \%$ of the starting amount. Recovery of $10 \mathrm{ng}$ with these kits is less efficient, especially for methylated DNA. EZ DNA Methylation-Gold Kit (Zymo Research) demonstrated more reasonable data for both types and quantities of DNA.

Processing of $80 \mathrm{ng}$ of the cirDNA from blood plasma of healthy controls and prostate cancer patients with CpGenome Fast DNA Modification Kit (Chemicon) resulted in better DNA yield than EpiTect Bisulfite Kit (Qiagen). Conversion of the cirDNAs by EZ DNA Methylation-Gold Kit (Zymo Research) demonstrated the highest possible DNA yield of $100 \%$ (Table 4) demonstrating in this way absence of usually occurred DNA degradation during bisulfite treatment and DNA loss during isolation [1].

Convergence (\%) of the data obtained by the kits (Table 4) was estimated as a $\min / \max$ variance of the mean data for different DNA recovery from solutions with different concentrations. The recovery of unmethylated DNA (500 ng, marked grey in Table 4) was selected as a reference and considered as zero. Data convergence reflects uniformity in the recovery of DNA of different sizes, structures, and compositions. EZ DNA Methylation-Gold Kit (Zymo Research) provided the most uniform yield of unmethylated, methylated genomic and circulating DNAs from the blood plasma of prostate cancer patients and healthy donors (Table 4). EpiTect Bisulfite Kit (Qiagen) and CpGenome Fast DNA Modification Kit (Chemicon) demonstrated a lower yield, especially at low DNA concentrations, and a significant variation of convergence $(-71 /+10$ and $-87 /+95$, respectively).

Table 4. Recovery of DNA after treatment with different commercial kits.

\begin{tabular}{|c|c|c|c|c|}
\hline \multirow{2}{*}{ DNA } & \multirow{2}{*}{ Initial amount } & Qiagen & Zymo Research & Chemicon \\
\hline & & Mean, $\%(\mathrm{SD})$ & Mean, \% (SD) & Mean, \% (SD) \\
\hline & $10 \mathrm{ng}$ & $5.8(0.05)$ & $92(8)$ & $2.7(0.2)$ \\
\hline \multicolumn{5}{|l|}{ Methylated } \\
\hline & $500 \mathrm{ng}$ & $22(4)$ & $68(3)$ & $19(7)$ \\
\hline & $10 \mathrm{ng}$ & $16(4)$ & $81(37)$ & $14(2)$ \\
\hline \multicolumn{5}{|l|}{ Unmethylated } \\
\hline & $500 \mathrm{ng}$ & $20(4)$ & $75(9)$ & $21(7)$ \\
\hline $\begin{array}{l}\text { Plasma cirDNA from healthy } \\
\text { controls }\end{array}$ & $80 \mathrm{ng}$ & $16(2)$ & $100(5)$ & $19(7)$ \\
\hline $\begin{array}{l}\text { Plasma cirDNA from prostate } \\
\text { cancer patients }\end{array}$ & $80 \mathrm{ng}$ & $11(1)$ & $100(5)$ & $41(13)$ \\
\hline Mean (SD) & & $15(3)$ & $86(16)$ & $19(7)$ \\
\hline Convergence, $\%$ (from/to) & & $-71 /+10$ & $-9 /+33$ & $-87 /+95$ \\
\hline
\end{tabular}


In sum, EZ DNA Methylation-Gold Kit from Zymo Research provided the highest yield of DNA after bisulfite treatment and isolation; the mean yield of DNA was no less than $86 \%$. In addition, the efficacy of DNA recovery after treatment with Zymo Research kit does not depend on starting DNA concentration. This is in contrast to other kits tested, which provided no more than $20 \%$ yield for high DNA concentrations and only $2.7-5.8 \%$ for low DNA concentrations. A low concentration of cirDNA in the blood and, correspondingly, low amounts of these DNAs available for analytical procedures along with their fragmentation as well as size and compositional diversity of DNA fragments demand the most efficient protocol of DNA bisulfite treatment. A high recovery rate of DNA after treatment with EZ DNA Methylation-Gold Kit demonstrates that this kit is the most appropriate for cirDNA treatment. Thus, the treatment of cirDNA from both healthy donors and cancer patients with EZ DNA Methylation-Gold Kit provides almost quantitative DNA recovery after treatment and confirms that this protocol can be recommended for treatment of cirDNA.

\section{Acknowledgements}

We thank M.D. Valentina Permyakova (Central Clinical Hospital, Siberian Branch of the Russian Academy of Sciences, Novosibirsk, Russia) and M.D. Sergey Yaromshchuk (Municipal Clinical Hospital no. 1, Novosibirsk, Russia.) for their helpful assistance in blood collection. This work was supported by Russian Academy of Sciences under the program "Basic Sciences for Medicine" and a DAAD scholarship Forschungsstipendien fuer Doktoranden und Nachwuchswissenschaftler № A 0775093 (2008) for Olga Bryzgunova.

\section{Competing Interests}

The authors do not receive any reimbursements, fees, funding, or salary from any organization that may in any way gain or lose financially from the publication of this manuscript, nor hold any stocks or shares from such an organization. The authors do not hold any patents relating to the theme of the manuscript nor have any relation with organizations that holds or have applied for such patents. The authors also do not have financial or non-financial competing interests.

\section{References}

[1] K. Munson, J. Clark, K. Lamparska-Kupsik and S. Smith, "Recovery of bisulfite-converted genomic sequences in the methylation-sensitive QPCR," vol. 35, Nucleic Acids Research, 2007, pp. 2893-2903.

[2] V. Vlassov, P. Laktionov and E. Rykova, "Extracellular nucleic acids," vol. 29, BioEssays, 2007, pp. 654-667.
[3] M. Fleischhacker and B. Schmidt, "Circulating nucleic acids (CNAs) and cancer--a survey," vol. 1775, Biochim. Biophys. Acta, 2007, pp. 181-232.

[4] M. Van der Vaart and P. Pretorius, "Is the role of circulating DNA as a biomarker of cancer being prematurely overrated," vol. 43, Clinical Biochemistry, 2010, pp. 26-36.

[5] K. Jung, M. Fleischhacker and A. Rabien, "Cell-free DNA in the blood as a solid tumor biomarker--a critical appraisal of the literature", vol. 411, Clin Chim Acta, 2010, pp. 16111624 .

[6] P. Laktionov, S. Tamkovich, E. Rykova, O. Bryzgunova, A. Starikov, N. Kuznetsova and V. Vlassov, "Free and cell surface bound nucleic acids in blood of healthy donors and breast cancer patients," vol. 1022, Ann N Y Acad Sci, 2004, pp. 221-227.

[7] P. Laktionov, S. Tamkovich, E. Rykovaand V. Vlassov, "Method of Nucleic acids isolation," Russian patent no. 2272072 from 20.03.2006.

[8] T. Skvortsova, E. Rykova, S. Tamkovich, O. Bryzgunova, A. Starikov, N. Kuznetsova, V. Vlassov and P. Laktionov, "Cellfree and cell-bound circulating DNA in breast tumours: DNA quantification and analysis of tumour-related gene methylation," vol. 94, Br J Cancer, 2006, pp. 1492-1495.

[9] V. Ngo, D. Gourdji, J, "LaverriereSite-specific methylation of rat prolactin and growth hormone promotors correlates with gene expression," vol. 16, Mol Cell Biol, 1996, pp. 3245-3254

[10] [10] S. Clark, J. Harrison and M. Frommer, " $\mathrm{CpNpG}$ methylation in mammalian cells" vol. 10, Nat Genet, 1995, pp. 20-27.

[11] A. Padar, U. Sathyanarayana, M. Suzuki, R. Maruyama, J. Hsieh, E. Frenkel, J. Minna and A. Gazdar, 'Inactivation of Cyclin D2 gene in Prostate Cancer by Aberrant Promoter Methylation," vol. 9, Clin Cancer Res, 2003, pp. 4730-4734.

[12] C. Jerynimo, R. Henrique, M. Hoque, F. Ribeiro, J. Oliveira, D. Fonseca, M. Teixeira, C. Lopes and D. Sidransky, "Quantitative RARbeta2 hypermethylation: a promising prostate cancer marker," vol. 10, Clin Cancer Res, 2004, pp. $4010-4014$

[13] Y. Korshunova, R. Maloney, N. Lakey, R. Citek, B. Bacher, A. Budiman, J. Ordway, W. McCombie, J. Leon, J. Jeddeloh and J. McPherson, "Massively parallel bisulphite pyrosequencing reveals the molecular complexity of breast cancer-associated cytosine-methylation patterns obtained from tissue and serum DNA," vol. 18, Genome Res, 2008, pp. 19-29.

[14] K. Reed, M. Poulin, L. Yan, A. Parissenti, "Comparison of bisulfite sequencing PCR with pyrosequencing for measuring differences in DNA methylation," vol. 397, Anal Biochem, 2010, pp. 96-106.

[15] A. Yang, M. Estecio, K. Doshi, Y. Kondo, E. Tajara and J. Issa, "A simple method for estimating global DNA methylation using bisulfite PCR of repetitive DNA elements," vol. 32, Nucl Acids Res, 2004, pp. e38.

[16] K. Jeong and S. Lee, "Estimating the total mouse DNA methylation according to the B1 repetitive elements," vol. 335, Biochem Biophys Res Commun, 2005, pp. 1211-1216. 
[17] J. Issa, V. Gharibyan, J. Cortes, J. Jelinek, G. Morris, S. Verstovsek, M. Talpaz, G. Garcia-Manero and H. Kantarjian, "Phase II study of low-dose decitabine in patients with chronic myelogenous leukemia resistant to imatinib mesylate," vol. 23, Clin Oncol, 2005, pp. 3948-3956.

[18] J. Dupont, J. Tost, H. Jammes and I. Gut, "De novo quantitative bisulfite sequencing using the pyrosequencing technology," vol. 333, Anal Biochem, 2004, pp. 119-127.

[19] E. Dejeux, V. Audard, C. Cavard, I. Gut, B. Terris, J. Tost, "Rapid identification of promoter hypermethylation in hepatocellular carcinoma by pyrosequencing of etiologically homogeneous sample pools," vol. 9, J Mol Diagn, 2007, pp. 510-520.

[20] E. Morozkin, T. Babochkina, V. Vlassov and P. Laktionov, "The Effect of Protein Transport Inhibitors on the Production of Extracellular DNA," vol. 1137, Ann N Y Acad Sci, 2008, pp. 31-36.

[21] L. Li, J. Choi, K. Lee, H. Sung, S. Park, I. Oze, K. Pan, W. You, Y. Chen, J. Fang, K. Matsuo, W. Kim, Y. Yuasa, D. Kang, "DNA Methylation in Peripheral Blood: A Potential Biomarker for Cancer Molecular Epidemiology," vol. 22, J Epidemiol, 2012, pp. 384-394. 